Jurnal Pengabdian Masyarakat

vol.1 no.1 Oktober 2017

\title{
PELATIHAN PENGGUNAAN SOFWARE STRUCTURAL ANALYSIS PROGRAM (SAP) PADA STRUKTUR BANGUNAN GEDUNG DI SEKOLAH MENENGAH KEJURUAN NEGERI 2 DUMAI Fitra Ramdhani $^{1)}$, Ahmad Zaki ${ }^{2)}$, Husnah ${ }^{3)}$ \\ ${ }^{1-3)}$ Program Studi S1 Teknik Sipil Fakultas Teknik Universitas Abdurrab
} fitraramdhani05@gmail.com

\begin{abstract}
Given the growing knowledge of science and technology and the Asean Economic Community (MEA) which imply high competency requirements to enter the workforce, it is necessary to have a partnership with SMK which is one of the most skilled labor producers in the industrial world. Therefore, we chose the Structural Analysis Program (SAP) Training Program in building building in order to increase and increase the students' knowledge, skills about software design in the workplace. There are three methods applied: 1) presentation method to introduce SAP software, provide material explanation about basic steps of using SAP software and exemplify how to use SAP program in some examples of simple building planning, high rise building and bridge, 2) demonstrations method for SAP operationalization of programs and direct exemplification of simple building designs; and 3) practical methods for practicing SAP software directly by students. With the use of SAP software training in SMK Negeri 2 Dumai provides new knowledge insight among vocational students while sitting in school they can only use autocad software alone can now use SAP software in planning building. From the results of the practice of using SAP software is almost all students can use this SAP software quickly which can be seen from the results of his practice.

Keywords: Software, Structural Analysis Program (SAP), Structure.
\end{abstract}

\begin{abstract}
ABSTRAK
Mengingat semakin berkembangnya ilmu pengetahuan dan teknologi serta Masyarakat Ekonomi Asean (MEA) yang berimplikasi pada persyaratan kompetensi yang tinggi untuk memasuki dunia kerja, menyebabkan perlunya dilakukan usaha kemitraan dengan SMK yang menjadi salah satu penghasil tenaga kerja terampil di dunia industri. Oleh karena itu kami memilih program Pelatihan Structural Analysis Program (SAP) pada bangunan gedung agar dapat menambah dan meningkatkan pengetahuan, keterampilan siswa tentang software design di dunia kerja. Ada tiga metode yang di terapkan yaitu: 1)metode presentasi untuk memperkenalkan sofware SAP, memberikan penjelasan materi mengenai langkah-langkah dasar penggunaan software SAP dan mencontohkan cara menggunakan program SAP tersebut dalam beberapa contoh perencanaan bangunan sederhana, gedung bertingkat dan jembatan, 2)metode demonstrasi untuk pengoperasionalisasi program SAP dan mencontohkan secara langsung desain bangunan sederhana, dan 3)metode praktek untuk melakukan praktek software SAP secara langsung oleh siswa. Dengan adanya pelatihan pengunaan sofware SAP di SMK Negeri 2 Dumai ini memberikan wawasan ilmu pengetahuan yang baru di kalangan siswa SMK yang selama duduk di bangku sekolah mereka hanya bisa menggunakan software autocad saja sekarang sudah bisa menggunakan software SAP dalam merencanakan bangunan gedung. Dari hasil praktek penggunaan Sofware SAP ini hampir semua siswa bisa menggunakan software SAP ini dengan cepat yang dapat dilihat dari hasil praktek nya.

Kata kunci: Sofware, Structural Analysis Program (SAP), Struktur.
\end{abstract}




\section{PENDAHULUAN}

Tantangan kecenderungan globalisasi, otonomi daerah perkembangan ilmu pengetahuan dan teknologi, serta Masyarakat Ekonomi Asean (MEA) yang berimplikasi pada persyaratan kompetensi yang tinggi untuk memasuki dunia kerja, menyebabkan perlunya dilakukan usaha kemitraan dengan SMK yang menjadi salah satu penghasil tenaga kerja terampil di dunia industri. Lebih dari satu dekade yang lalu, wakil negara negara Asean melakukan kesepakatan dalam pembentukan sebuah pasar tunggal dikawasan asia tenggara pada akhir tahun 2015. Kesepakatan ini menitik beratkan pembentukan kawasan ASEAN yang stabil, makmur dan kompetitif dengan pertumbuhan ekonomi yang adil dan merata serta dapat mengurangi kemiskinan dan kesenjangan sosial. Tamatan SMK perlu diperkaya kemampuannya dengan softwere pendukung agar mampu bersaing dengan tenaga kerja asing yang akan masuk ke Indonesia. Sosialisasi dan pelatihan ini yang akan dilakukan lebih menitik beratkan pada cara tepat dan cepat dalam menggunakan salah satu softwere Teknik Sipil dan penggunaanya dalam dunia kerja teknik sipil.

Berdasarkan analisis situasi dan fakta di lapangan, maka dalam pengabdian kepada masyarakat ini dilakukan pada Siswa SMK Negeri 2 Dumai yang mana mereka belum mengenal softwere Structural Analysis Program (SAP) ini. Dipilihnya sasaran tersebut dengan pertimbangan bahwa sebelum siswa tersebut memasuki pendidikan ke perguruan tinggi khususnya jurusan teknik sipil, mereka sudah dibekali sejak awal konsep dan perubahan di ilmu teknik sipil sehingga memudahkan mereka pada saat diperguruan tinggi nantinya. Dengan demikian meskipun mereka dari desa dan jarak yang ditempuh untuk sampai ke universitas relatif jauh pelajar tersebut tidak ketinggalan informasi dan tetap memiliki wawasan yang luas mengenai perkembangan ilmu pengetahuan khususnya dibidang teknik sipil.

Oleh karena itu kami memilih program Pelatihan Structural Analysis Program (SAP) pada bangunan gedung agar dapat menambah dan meningkatkan pengetahuan, keterampilan siswa tentang softwere design di dunia kerja.

\section{METODE}

Pengabdian ini dilaksanakan pada hari Jumat tanggal 03 Maret 2017 di SMK Negeri 2 Dumai. Pelaksanaan kegiatan pengabdian kepada masyarakat ini dilakukan dengan metode ceramah, demontrasi dan praktik (Pelatihan penggunaan software SAP ini pada struktur gedung yaitu dan praktek langsung sehingga siswa paham konsep dan praktik dari apa yang telah disampaikan)

Ada tiga metode yang di terapkan dalam program pelatihan ini antara lain yaitu :

1. Metode presentasi diterapkan untuk memperkenalkan sofware SAP, memberikan penjelasan materi mengenai langkah-langkah dasar penggunaan software SAP dan mencontohkan cara menggunakan program SAP tersebut dalam beberapa contoh perencanaan bangunan sederhana, gedung bertingkat dan jembatan.

2. Metode demonstrasi dilakukan untuk mengenai pengoperasionalisasi program SAP, mencontohkan secara langsung desain bangunan sederhana.

3. Metode Praktek yaitu dimana siswa-siswa mempratekkan secara langsung menggambar desain bangunan gedung seperti yang telah di demontrasikan. Metode praktek ini dilakukan dengan cara membuat kelompok-kelompok siswa dimana setiap kelompok mempraktekkan cara penggunaan software SAP ini dengan soal yang telah diberikan. 
Jurnal Pengabdian Masyarakat

vol.1 no.1 Oktober 2017

\section{HASIL DAN PEMBAHASAN}

Dalam pelaksanaan pelatihan ini dengan memberikan soal perencanaan gedung bertingkat 5 seperti yang dijelaskan pada soal di bawah ini:

Soal:

Dimensi Balok 25/50

Dimensi kolom 50/50

Mutu beton fc : $25 \mathrm{Mpa}$

Mutu Baja , BJTD = $400 \mathrm{Mpa}$

$$
\mathrm{BJTP}=240 \mathrm{Mpa}
$$

Penutup beton pada balok dan kolom $40 \mathrm{~mm}$

Data pembebanan :

- Beban mati balok adalah $7 \mathrm{kN} / \mathrm{m}$ (balok tepi) dan $14 \mathrm{kN} / \mathrm{m}$ (balok tengah)

- Beban hidup balok adalah $6 \mathrm{kN} / \mathrm{m}$ (balok tepi) dan $12 \mathrm{kN} / \mathrm{m}$ (balok tengah)
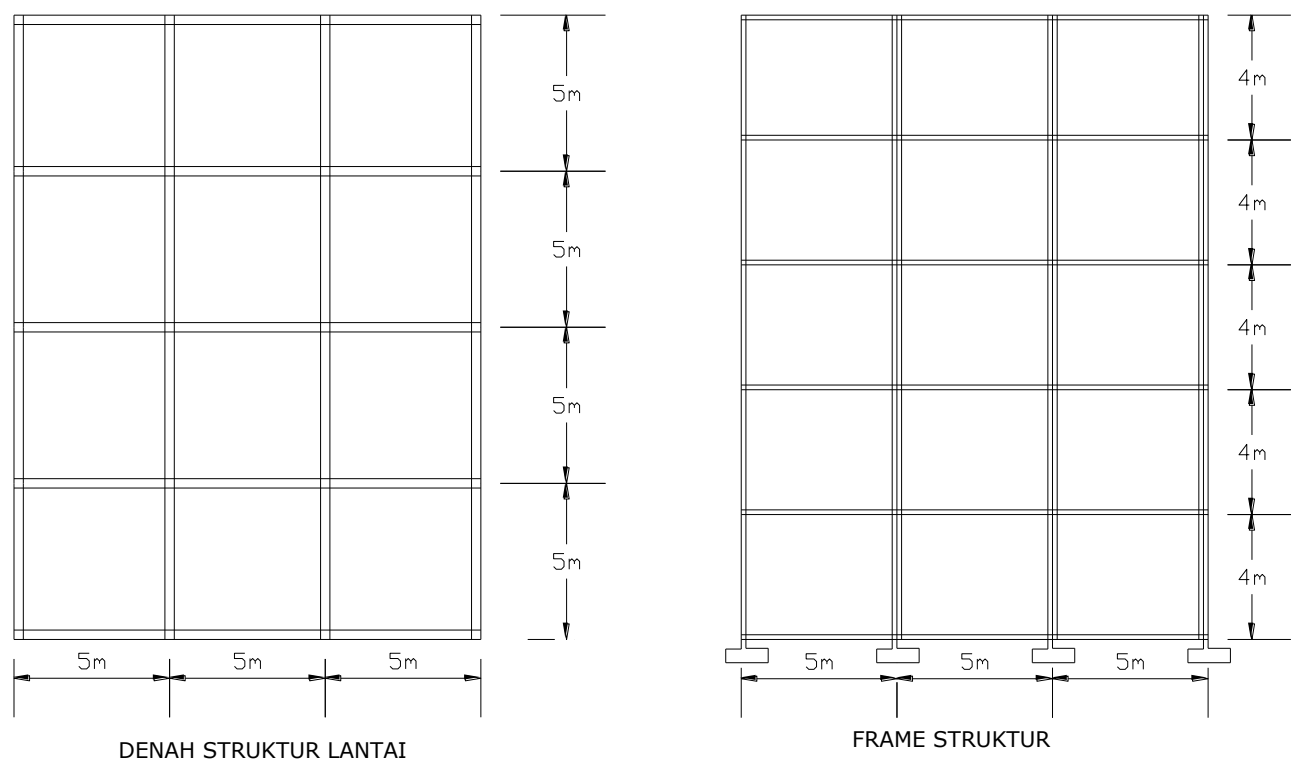

Adapun 10 langkah utama analisa sap 2000 adalah sebagai berikut:

1. Samakan Satuan

2. Buat Model Struktur

3. Define Material yang dipakai

4. Define Profil yang dipakai

5. Aplikasikan Profil pada Struktur

6. Define Beban

7. Aplikasikan Beban

8. Cek Gambar Struktur - Model Sap2000

9. Run Analisa

10. Cek the result 
Jurnal Pengabdian Masyarakat

vol.1 no.1 Oktober 2017

Hasil Praktek Pelatihan SAP:

1. Gambar Gedung bertingkat 5

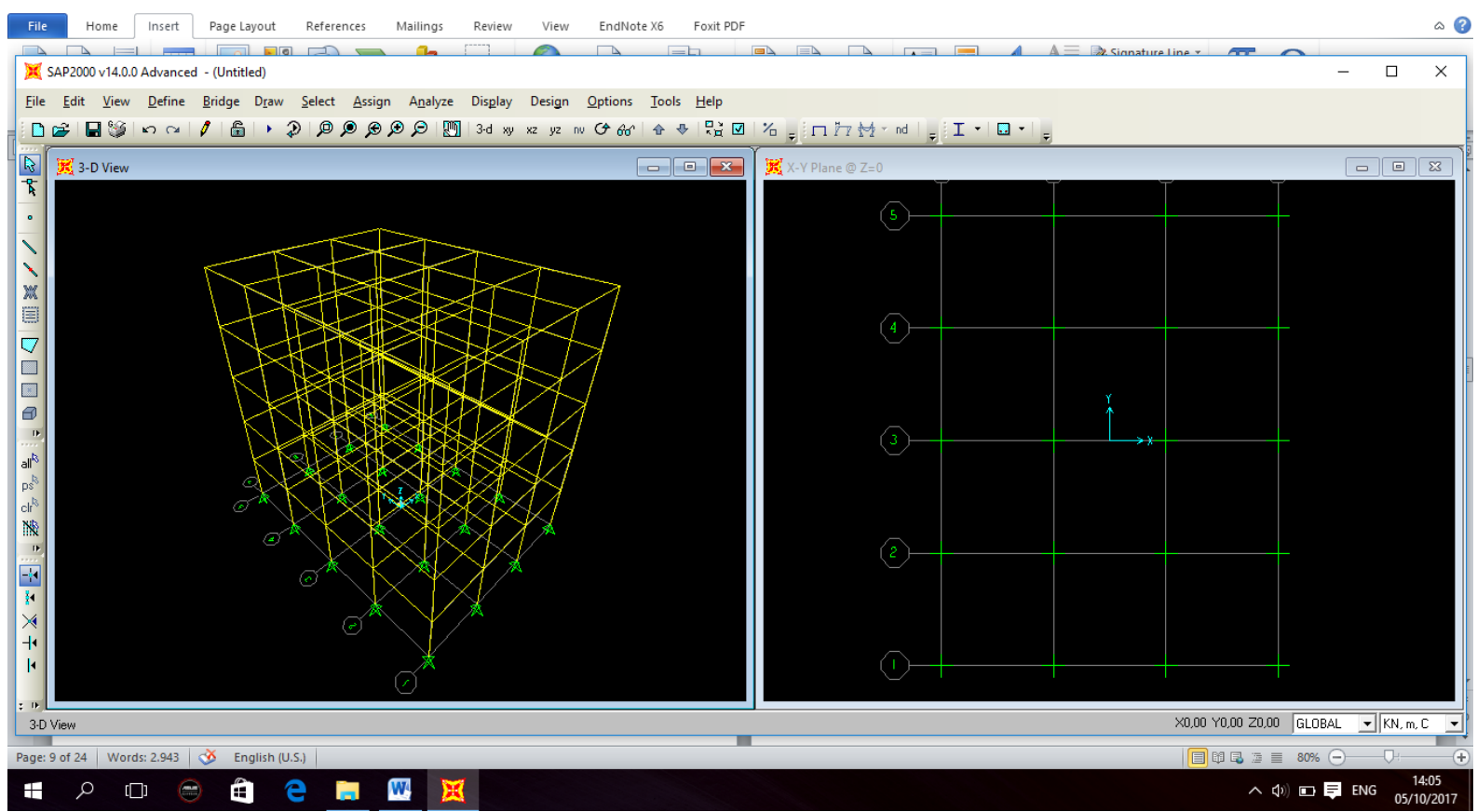

Gambar 1. Model Gedung Bertingkat 5

2. Gambar Balok 25/50 dan Kolom 50/50

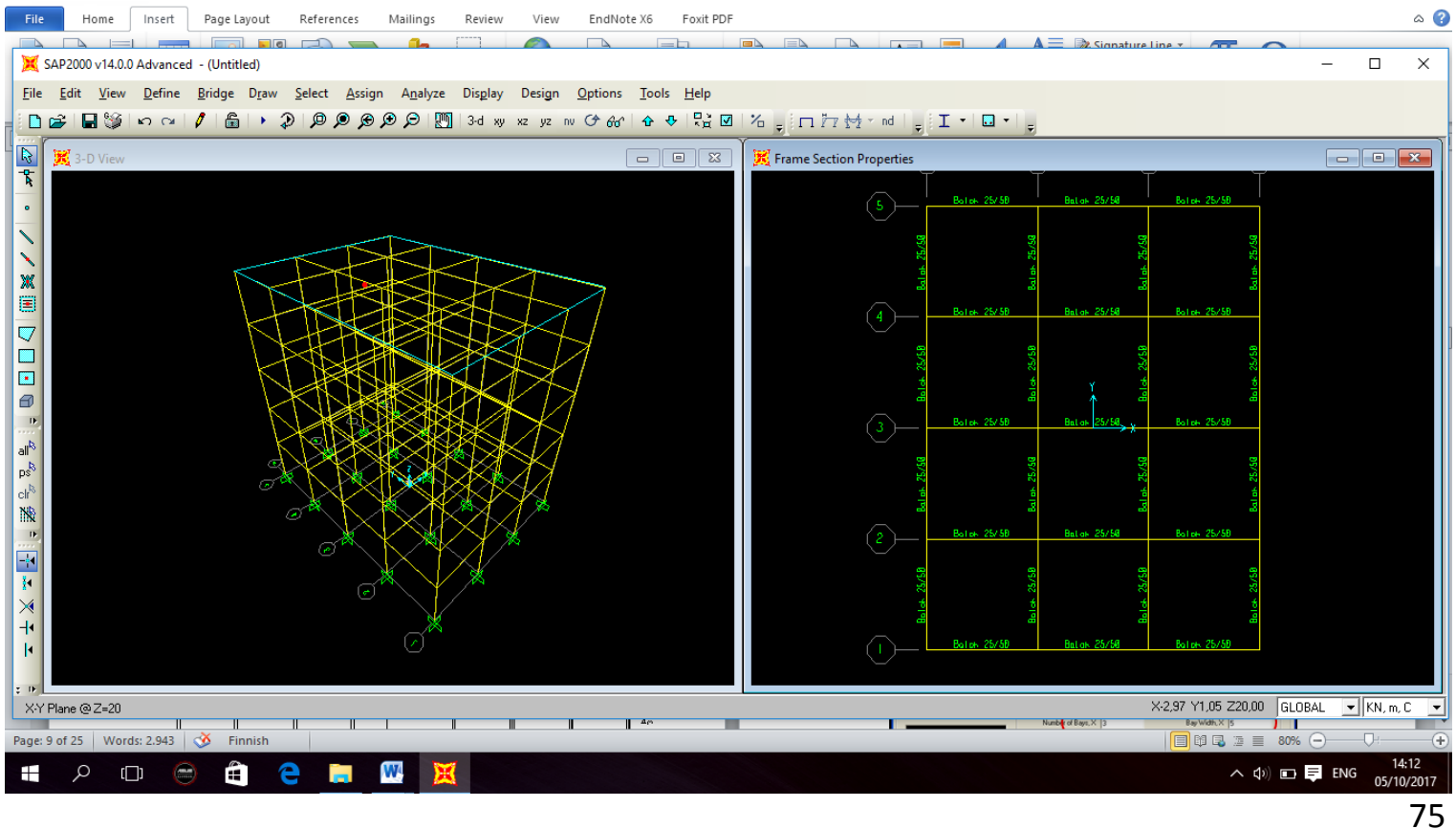


Jurnal Pengabdian Masyarakat

vol.1 no.1 Oktober 2017

Gambar 2. Dimensi Balok 25/50

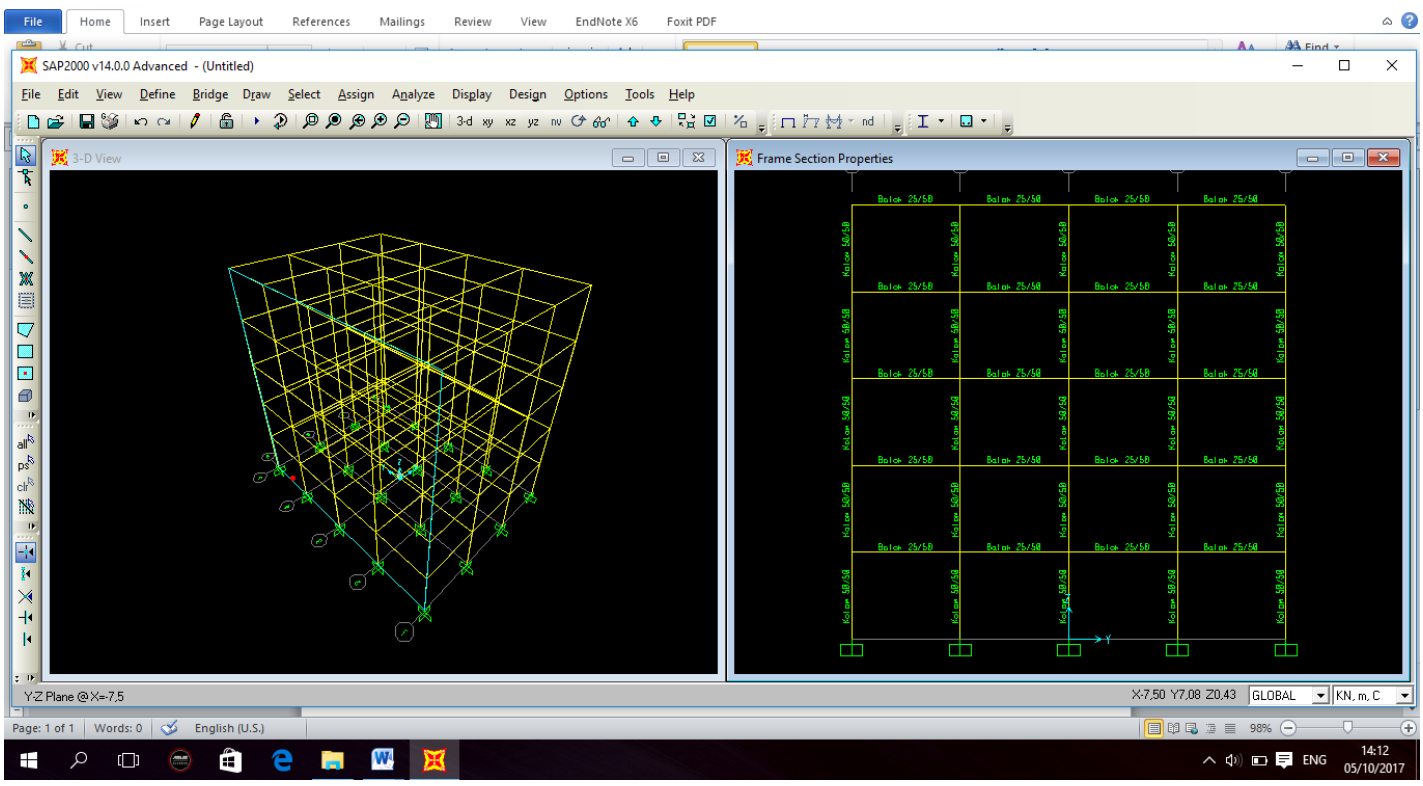

Gambar 3. Dimensi Kolom 50/50

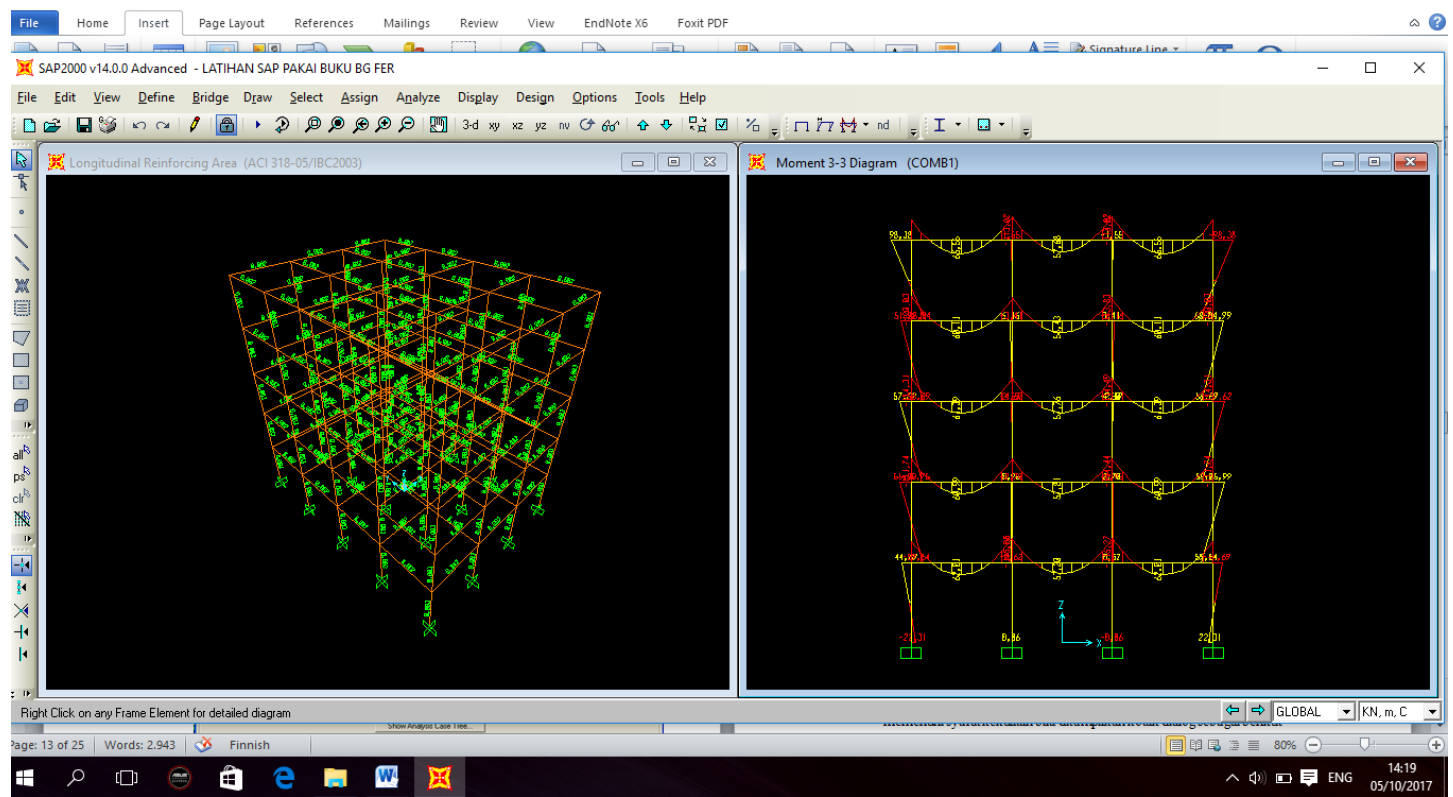

Gambar 4. Hasil Design Gedung Bertingkat 5 
Jurnal Pengabdian Masyarakat

vol.1 no.1 Oktober 2017

\begin{tabular}{|c|c|c|c|c|c|c|c|c|c|c|c|}
\hline \multicolumn{12}{|c|}{ Element Forces - Frames } \\
\hline File & View & Format- & Filter-Sort Se & ect Options & & & & & & & \\
\hline \multicolumn{6}{|c|}{ Units: As Noted } & \multicolumn{4}{|c|}{ Element Forces - Frames } & \multicolumn{2}{|r|}{ I. } \\
\hline & & $\begin{array}{r}\text { Station } \\
\mathrm{m}\end{array}$ & \begin{tabular}{|c|} 
OutputCase \\
Text
\end{tabular} & $\begin{array}{c}\text { CaseType } \\
\text { Text }\end{array}$ & $\begin{array}{r}\mathbf{P} \\
\mathbf{K N}\end{array}$ & $\begin{array}{l}\mathrm{V} 2 \\
\mathrm{KN}\end{array}$ & $\begin{array}{l}\mathrm{V} 3 \\
\mathrm{KN}\end{array}$ & $\begin{array}{r}\mathbf{T} \\
\mathrm{KN}-\mathrm{m}\end{array}$ & $\begin{array}{r}\mathrm{M} 2 \\
\mathrm{KN}-\mathrm{m}\end{array}$ & $\begin{array}{r}\mathrm{M3} \\
\mathrm{KN}-\mathrm{m} \\
\end{array}$ & $\Delta$ \\
\hline \multirow[t]{20}{*}{$\nabla$} & & 0 & COMB1 & Combination & $-2563,776$ & $.16,748$ & $-16,919$ & $-1,829 \mathrm{E}-15$ & $.22,6643$ & $-22,3056$ & \\
\hline & & 2 & COMB1 & Combination & $-2445,05$ & $-16,748$ & $-16,919$ & $-1,829 \mathrm{E}-15$ & 11,1732 & 11.1903 & \\
\hline & & 4 & COMB1 & Combination & $-2326,325$ & $-16,748$ & $-16,919$ & $-1,829 \mathrm{E}-15$ & 45,0106 & 44,6861 & \\
\hline & & 0 & COMB1 & Combination & $-2055,534$ & $-28,885$ & $-28,761$ & $-3,085 \mathrm{E}-15$ & $-59,2294$ & $-59,5443$ & \\
\hline & & 2 & COMB1 & Combination & $-1936,809$ & $.28,885$ & $-28,761$ & $-3,085 \mathrm{E}-15$ & $-1,7075$ & $-1,7748$ & \\
\hline & & 4 & COMB1 & Combination & $-1818,083$ & $-28,885$ & $-28,761$ & $-3,085 \mathrm{E}-15$ & 55,8145 & 55,9946 & \\
\hline & & 0 & COMB1 & Combination & $-1542,128$ & $.28,342$ & $-28,328$ & $-4,498 \mathrm{E} \cdot 15$ & $-55,8332$ & $-55,747$ & \\
\hline & & 2 & COMB1 & Combination & $-1423,403$ & $-28,342$ & $-28,328$ & $-4,498 \mathrm{E}-15$ & 0.8236 & 0,9371 & \\
\hline & & 4 & COMB1 & Combination & $-1304,677$ & $-28,342$ & $-28,328$ & $-4,498 \mathrm{E}-15$ & 57,4805 & 57,6212 & \\
\hline & & 0 & COMB1 & Combination & $-1026,265$ & $-27,169$ & $-27,397$ & $-5,563 \mathrm{E}-15$ & $-56,9584$ & $-56,6889$ & \\
\hline & & 2 & COMB1 & Combination & $.907,54$ & $-27,169$ & $-27,397$ & $-5,563 \mathrm{E}-15$ & $-2,1645$ & $-2,3508$ & \\
\hline & & 4 & COMB1 & Combination & $.788,815$ & $.27,169$ & $-27,397$ & $-5,563 \mathrm{E}-15$ & 52,6294 & 51,9872 & \\
\hline & & 0 & COMB1 & Combination & $-506,973$ & $-41,605$ & $-41,24$ & $-4,372 \mathrm{E} \cdot 15$ & $-67,1701$ & $-68,0423$ & \\
\hline & & 2 & COMB1 & Combination & $-388,248$ & $-41,605$ & $-41,24$ & $-4,372 E-15$ & 15,3098 & 15,1685 & \\
\hline & & 4 & COMB1 & Combination & $-269,522$ & $-41,605$ & $-41,24$ & $-4,372 \mathrm{E}-15$ & 97,7896 & 98,3793 & \\
\hline & & 0 & COMB1 & Combination & $-3253,619$ & $-16,748$ & $-0,063$ & $-1,731 \mathrm{E}-15$ & $-0,3872$ & $-22,3056$ & \\
\hline & & 2 & COMB1 & Combination & $-3134,893$ & $-16,748$ & $-0,063$ & $-1,731 \mathrm{E}-15$ & $-0,2613$ & 11,1903 & \\
\hline & & 4 & COMB1 & Combination & $-3016,168$ & $-16,748$ & $-0,063$ & $-1,731 \mathrm{E}-15$ & $-0,1355$ & 44,6861 & \\
\hline & & 0 & COMB1 & Combination & $-2602,626$ & $.28,885$ & 0,061 & $-4,178 \mathrm{E}-15$ & 0,884 & $-59,5443$ & \\
\hline & & 2 & COMB1 & Combination & $-2483,901$ & $.28,885$ & 0,061 & $-4,178 \mathrm{E}-15$ & 0,7629 & $-1,7748$ & $\vec{v}$ \\
\hline 1 & & & & & & & & & & • & \\
\hline Recor & ird: $\mathbf{1}$ & \begin{tabular}{|l|l|}
14 \\
\end{tabular} & $1 \backslash \mid M$ of & 2005 & & & & & Add Tables... & Done & \\
\hline
\end{tabular}

Gambar 5. Hasil Perhitungan Momen dari Sofware SAP

\section{DOKUMENTASI KEGIATAN}

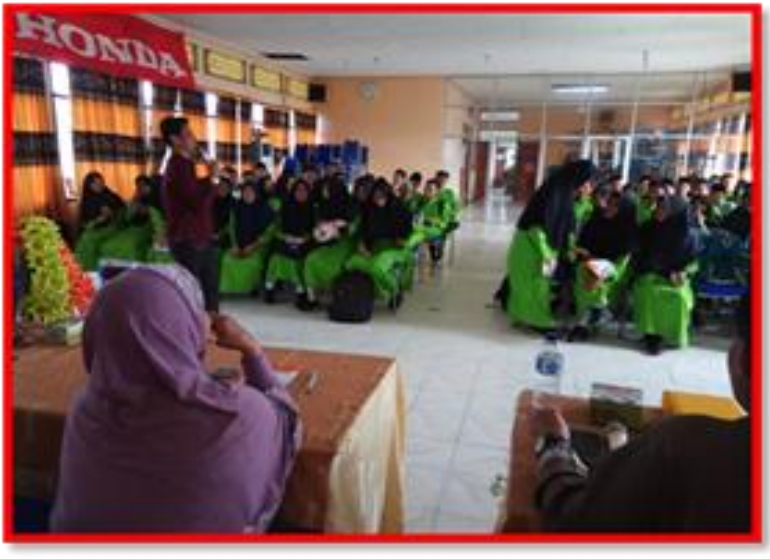

Gambar 1

Pembukaan oleh MC

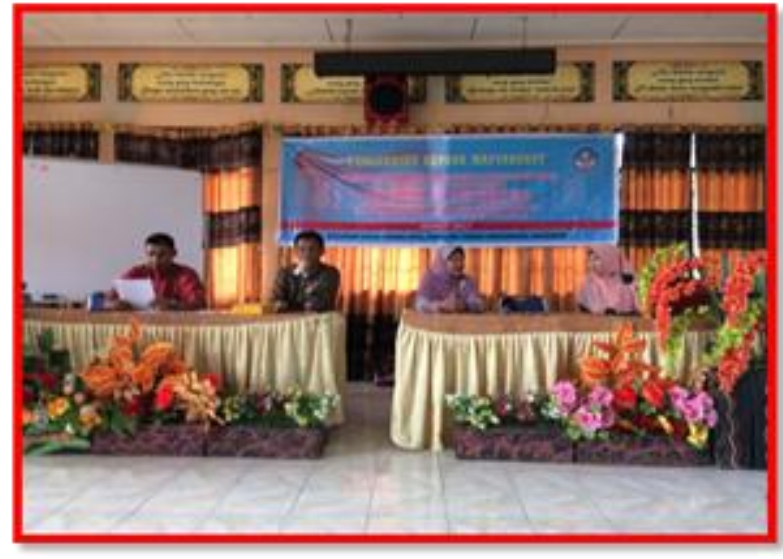

Gambar 2

Kata Sambutan Kepala Sekolah SMKN 2

Dumai 


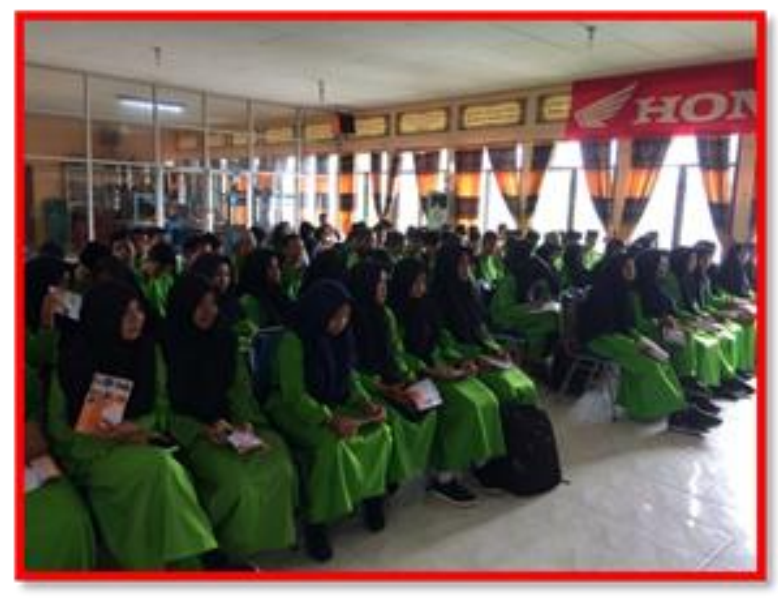

Gambar 3

Peserta Pengabdian Siswa SMKN 2 Dumai

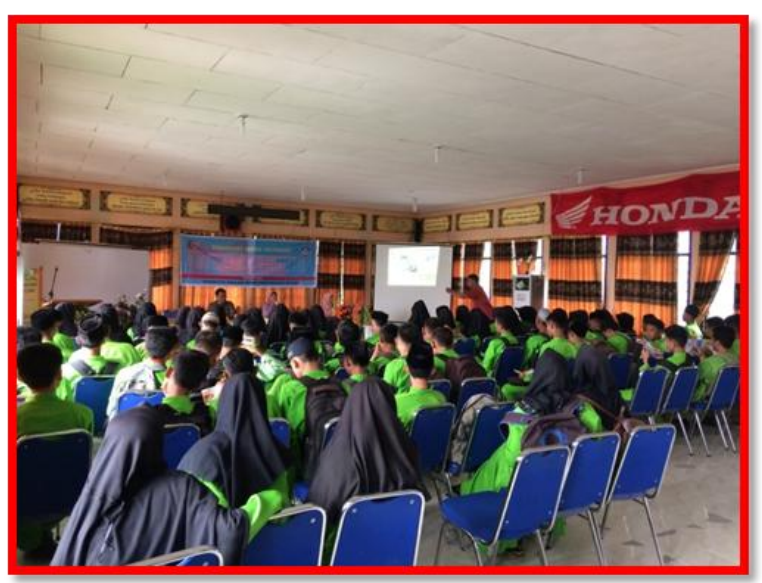

Gambar 4

Peserta Pengabdian Siswa SMKN 2 Dumai

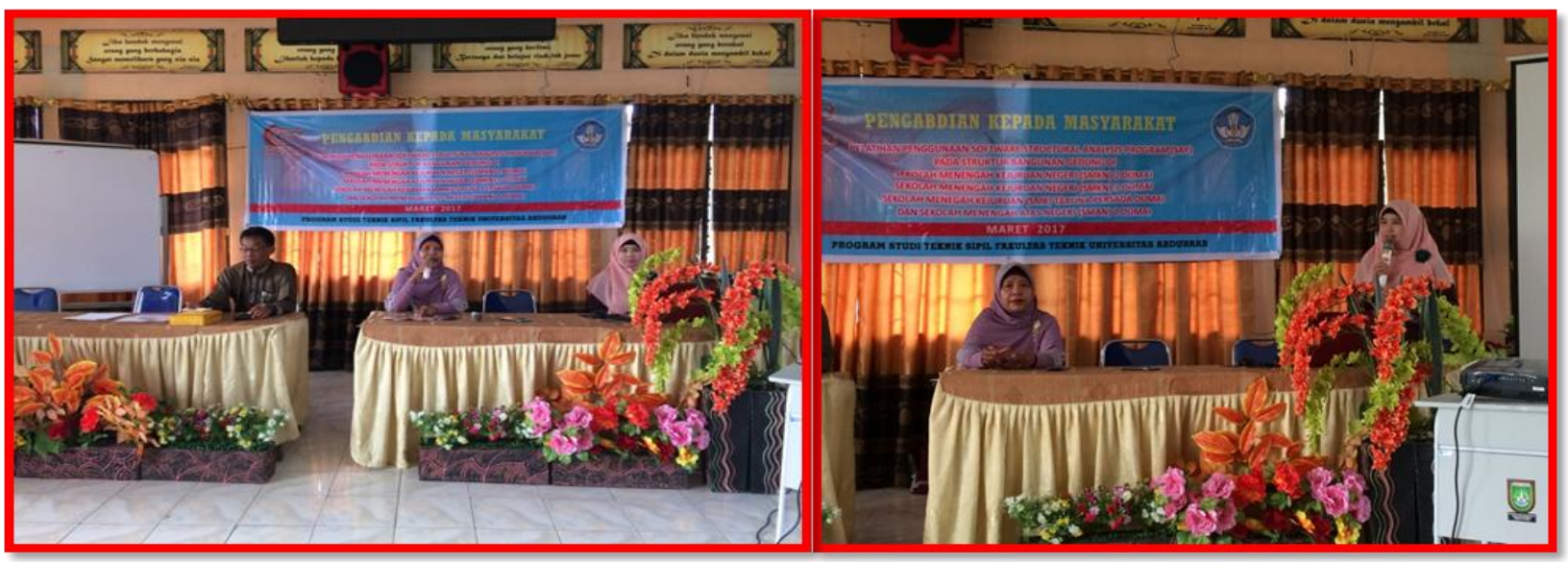

Gambar 5

Kata Sambutan Wakil Kepala Sekolah SMKN 2 Dumai
Gambar 6

Kata Sambutan Ketua Tim Pengabdian (Fitra Ramdhani, M.T) SMKN 2 Dumai 


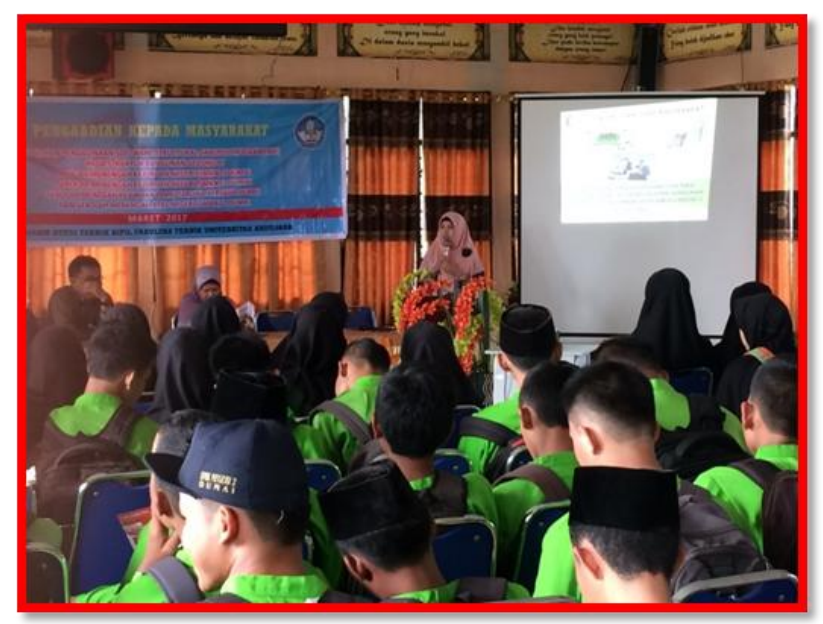

Gambar 7

Pemberian Materi Pelatihan

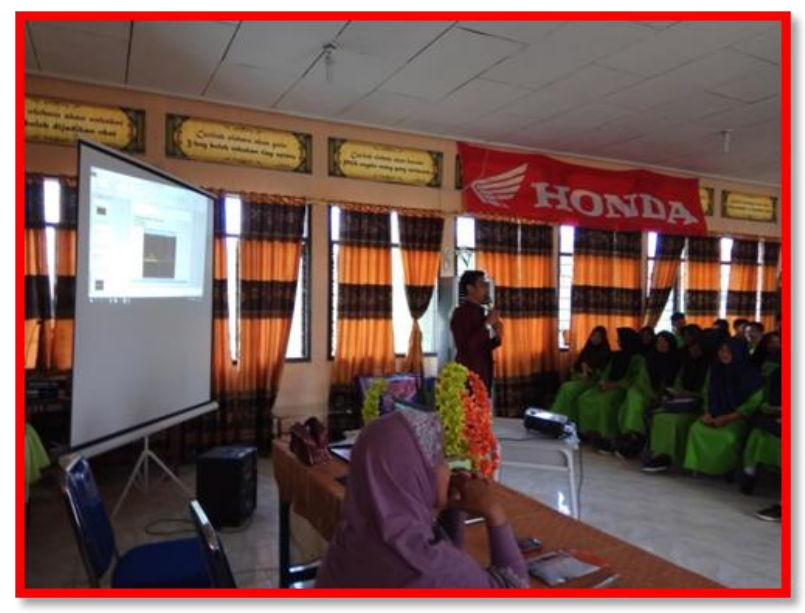

Gambar 9

Presentasi Hasil Praktek

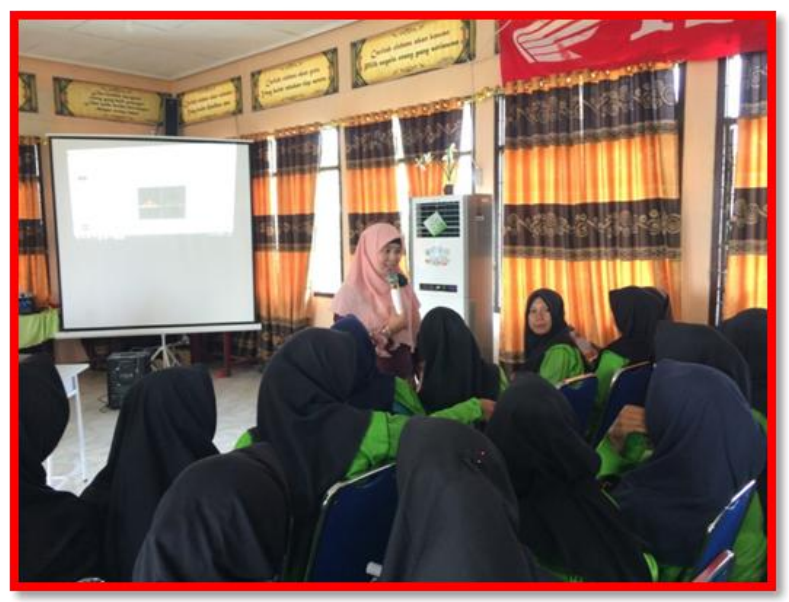

Gambar 8

Demontrasi Materi Pelatihan

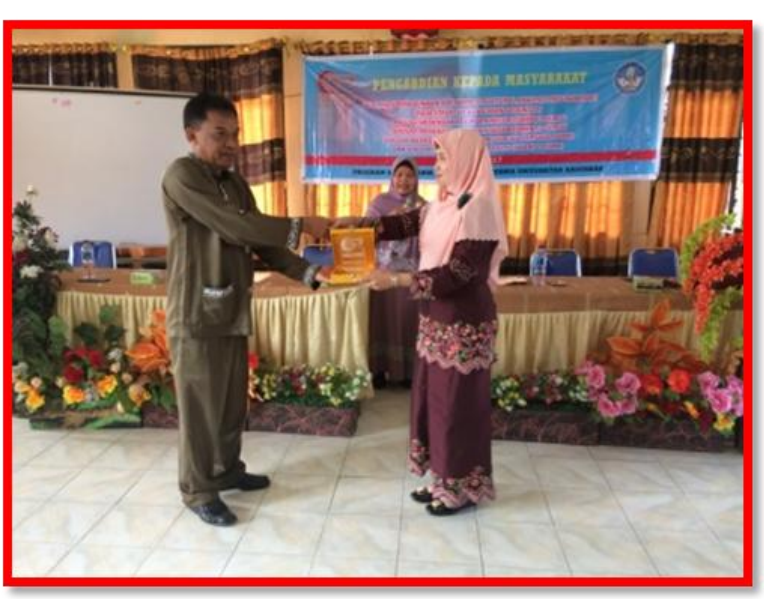

Gambar 10

Pemberian Cendramata plakat 


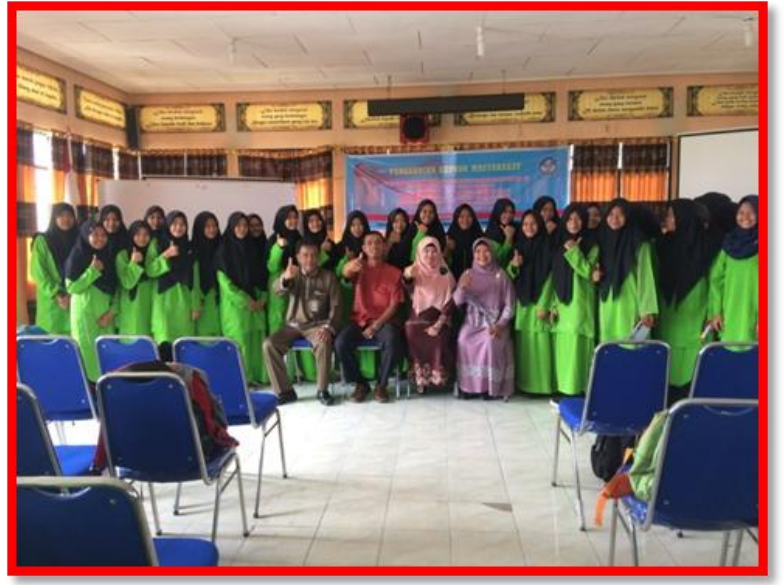

Gambar 11

Foto Bersama Tim PPM, Guru dan siswa SMKN2

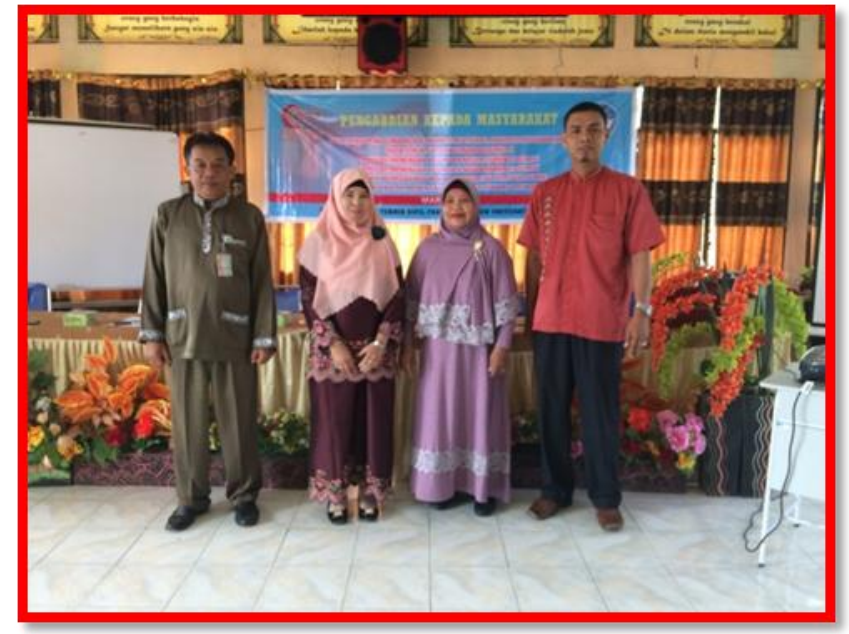

Gambar 12

Foto Bersama Tim PPM, Guru

\section{KESIMPULAN}

Dari hasil kegiatan pengabdian ini siswa siswi di SMK N 2 Dumai sudah mengetahui program SAP 2000 dalam perencanaan struktur bangunan selain program lainnya seperti autocad dan shechup. Hasil praktek ini sebagai indikator untuk mengetahui sejauh mana keberhasilan materi dan pemahaman materi yang telah disampaikan. Dari hasil praktek penggunaan Sofware SAP ini hampir semua siswa bisa menggunakan software SAP ini dengan cepat yang dapat dilihat dari hasil praktek nya. Hal ini dapat menjadi bekal mereka apabila melanjutkan studi di program studi Teknik Sipil,

\section{DAFTAR PUSTAKA}

[1] Badan Standarisasi Nasional (2012) Beban Minimum Untuk Perencanaan Bangunan Gedung dan Struktru Lain SNI 1727-2013. Jakarta

[2] Computer and Structures, Inc (2005) CSI Analysis Reference Manual For SAP 2000, ETABS and SAFE, Barkeley, California

[3] Computer and Structures, Inc (2005) CSI Analysis Reference For SAP 2000, ETABS and SAFE, Barkeley, USA

[4] Fardheny, Arie Febri , MT(2006) "SAP 2000 for Beginners" SAP 2000 Using V8.0 - V 9.0 - V10.0

[5] Republika, (2015) Kedepannya pemerintah akan menargetkan presentasi SMK dan SMA berbanding 60 : 40" 